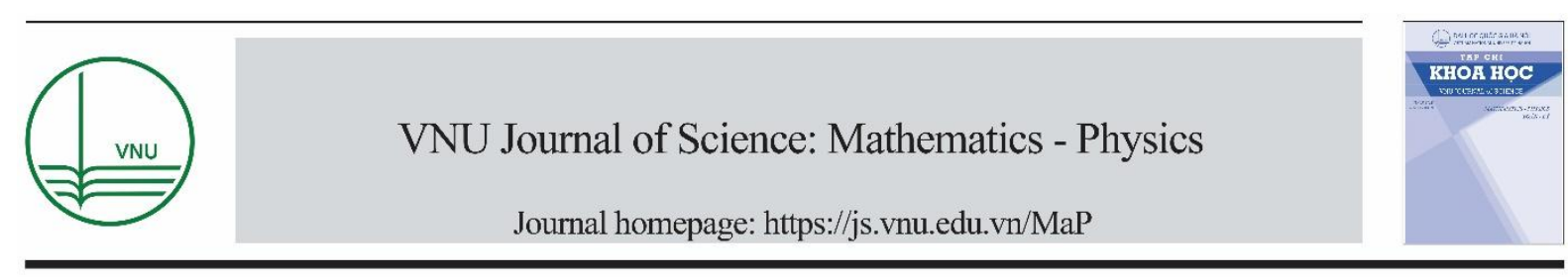

Original Article

\title{
Study of Structure Transition and Crystallization of Amorphous Silica under Compression
}

\author{
Giap Thi Thuy Trang ${ }^{1,2}$, Pham Huu Kien ${ }^{1, *}$ \\ ${ }^{I}$ Thai Nguyen University of Education, 20 Luong Ngoc Quyen, Thai Nguyen, Vietnam \\ ${ }^{2}$ Ha Noi University of Science and Technology, 1 Dai Co Viet, Hanoi, Vietnam
}

Received 29 October 2019

Revised 13 December 2019; Accepted 25 December 2019

\begin{abstract}
In this work, we use molecular dynamic (MD) simulation to study the structure transition and crystallization of amorphous silica $\left(\mathrm{SiO}_{2}\right)$ under compression. The structural evolution of amorphous $\mathrm{SiO}_{2}$ is explained through radial distribution function, coordination number distribution, bond angle distribution and visualization. Simulation result shown that there is a structural transformation from tetrahedral to octahedral network through $\mathrm{SiO}_{5}$ units. In the 5$15 \mathrm{GPa}$ pressure range, structural transformation occurs powerfully and there are three structural phases corresponding to $\mathrm{SiO}_{4-}, \mathrm{SiO}_{5^{-}}$, and $\mathrm{SiO}_{6-}$ ones. At $15 \mathrm{GPa}$, octahedral-network $\left(\mathrm{SiO}_{6}\right)$ is dominant. It is the first time we showed that when pressure is higher than $20 \mathrm{GPa}$, octahedralnetwork of amorphous $\mathrm{SiO}_{2}$ has a tendency to transform to stishovite crystalline phase.
\end{abstract}

Keywords: Compression, crystallization, structural transformation, phase, amorphous.

\section{Introduction}

Structural phase transformation under pressure of $\mathrm{SiO}_{2}$ is interesting that it is great importance in technology and geophysics [1-5]. The wide range distribution of Si-O-Si bond angle and bond length in silica gives rise to a rich variety of structures of phases in this system as functions of pressure and temperature. The laxity of the structure is the important condition of existence of the glass state. It accounts for the specific glass-forming properties of $\mathrm{SiO}_{2}$ and for the very low ability of forming crystalline of amorphous silica. The behavior of various high pressure silica phases has been investigated by both theory and experiment for a long time [6-10]. For instance, using the firstprinciples ${ }^{29} \mathrm{Si} \mathrm{NMR}$ analysis, Mauri et al. [11] reported that the structural transformations at low-

\footnotetext{
${ }^{*}$ Corresponding author.

Email address: phamhuukien@dhsptn.edu.vn
}

https//doi.org/ 10.25073/2588-1124/vnumap.4422 
pressure are only accompanied by changes $\mathrm{Si}-\mathrm{O}-\mathrm{Si}$ bond angle without the change in local structure of $\mathrm{Si}$. The coordination change from $\mathrm{SiO}_{4}$ to $\mathrm{SiO}_{6}$ is only observed experimentally at pressures beyond 8 $\mathrm{GPa}(700 \mathrm{~K})$ by the formation of stishovite. Using MD simulation, Teter et al. [6] also reported that at pressure beyond $50 \mathrm{GPa}$, stishovite transforms to a phase having the $\mathrm{CaCl}_{2}$ structure type, which also contains $\mathrm{SiO}_{6}$. Increases in $\mathrm{Si}$ coordination have also been observed from spectroscopic and diffraction measurements of statically compressed silica glass/quartz at room temperature. Using MD simulations with an ab initio parameterized potential, Liu et al. [12] revealed the transformation pathways leading to a high pressure octahedral (HPO) phase. HPO phase has an $\mathrm{O}$ atoms hcp sub-lattice featuring and some point defects. They also showed that the HPO phase formed via a continuous rearrangement of the hcp sub-lattice. Meanwhile, the high pressure amorphous phases were described by an fcc and hcp sub-lattice mixture. Based on X-ray diffraction and ab initio simulations, Bykova et al. [13] suggested that $\mathrm{SiO}_{2}$ liquid in Earth's lower mantle has complex structures making them more compressible than previously supposed. S. Petitgirard et al. [14] has used X-ray Raman scattering spectroscopy and MD simulations to study of $\mathrm{SiO}_{2}$ melts. They found that coordination higher than 6 is only reached beyond $140 \mathrm{GPa}$, corroborating results from Brillouin scattering. Network modifying elements in $\mathrm{SiO}_{2}$ melts may shift this change in coordination to lower pressures and thus magmas could be denser than residual solids at the depth of the core-mantle boundary. Wu et al. [15] used x-ray Raman scattering (XRS), Brillouin scattering and diffraction to study on $\mathrm{SiO}_{2}$ glass. They found that the origin of the 'two peaks' pattern in the XRS was found to be the result of increased packing of O near the Si atom. The compression mechanism connected the presence of 5- and 6-fold coordinated silicon. A slight increase in the $\mathrm{Si}-\mathrm{O}$ coordination higher than 6 was found to accompany the increase in the acoustic wave velocity near pressure of $140 \mathrm{GPa}$. Most of the observed stable and metastable crystalline phases of silica consists of either $\mathrm{SiO}_{4}$ or $\mathrm{SiO}_{6}$ units [16, 17]. P.K. Hung et al. [19] has used MD simulations to investigate the a-quartz under nonhydrostatic stress found evidence for a crystalline phase of $\mathrm{SiO}_{2}$ composed entirely of $\mathrm{SiO}_{5}$ units. However, the network structure as well as the crystallization of amorphous silica under compression is still in debate. We just found a few the publishing about crystallization process of amorphous $\mathrm{SiO}_{2}$.

Therefore in this work, we focused on considering the structure transition and crystallization of amorphous $\mathrm{SiO}_{2}$ at $450 \mathrm{~K}$ and in pressure range from 0 to $30 \mathrm{GPa}$ via analysis of RDF, coordination number distribution, bond angle distribution, visualization, the characteristics and distribution of basic structural units $\mathrm{SiO}_{4}, \mathrm{SiO}_{5}$ and $\mathrm{SiO}_{6}$.

\section{Computational Procedure}

The periodic boundary conditions and the van Beest, Kramer, van Santen (BKS) potential are adopted [18] because it is simple. It can produce amorphous silica models with structural properties, density and thermal expansion that is in good agreement with experimental data [19-23]. It had following formula:

$$
U_{i j}\left(r_{i j}\right)=\frac{q_{i} q_{j}}{r_{\mathrm{ij}}}+A_{i j} e^{-B_{i j} r_{i j}}-\frac{C_{i j}}{r_{\mathrm{ij}}^{6}}
$$

where, $r_{i j}$ is the distance between two atoms $i$ and $j ; q_{i}$ and $q_{j}$ are the charges of $i$ and $j$, respectively; $A_{i j}, B_{i j}$ and $C_{i j}$ are constants. In expression (1), the first term $\left(\frac{q_{i} q_{j}}{r_{\mathrm{ij}}}\right):$ describes the 
Coulomb interaction between ions. The second term $\left(A_{i j} e^{-B_{i j} r_{i j}}\right):$ describes the pushing interaction at a distance close to the dominant electronic-electronic interaction and appears as the atoms come so close that their electronic clouds overlap each other. The last term: $\left(-\frac{C_{i j}}{r_{i j}^{6}}\right)$ describes the interaction at a close distance derived from the distribution of electrons in the atom that make up the dipole - dipole interaction. The BKS potential constants are determined by the optimization of the parameters in the simulation so that the calculation results are more empirical; This helps the model to be built based on the BKS potential close to the real system. The values of potential constants corresponding to the $\mathrm{Si}-\mathrm{O}$ and O$\mathrm{O}$ atom pairs are listed in Table 1; disregard the near interaction potential between $\mathrm{Si}-\mathrm{Si}$ atomic pairs.

Table 1. The parameters of BKS potential for $\mathrm{SiO}_{2}$

\begin{tabular}{|c|c|c|c|c|}
\hline Pairs & $A_{i j}(\mathrm{eV})$ & $B_{i j}\left(\AA^{-1}\right)$ & $C_{i j}\left(\mathrm{eV} \AA^{6}\right)$ & Charges $(\mathrm{e})$ \\
\hline $\mathrm{O}-\mathrm{O}$ & 1388.773 & 2.760 & 175.0 & $\mathrm{q}_{\mathrm{o}}=-1.2$ \\
\hline $\mathrm{Si}-\mathrm{O}$ & 18003.757 & 4.873 & 33.538 & $\mathrm{q}_{\mathrm{Si}}=+2.4$ \\
\hline $\mathrm{Si}-\mathrm{Si}$ & 0.0 & 0.0 & 0.0 & \\
\hline
\end{tabular}

The BKS models have played a significant role in numerous works of silica and related materials in the area of Materials Science as well as Geophysics. Namely, the BKS models was used to build silica models in different states, for example amorphous [21-23], crystals [24, 25 ] and liquid silica $[26,27]$. In ref. [24, 25] compared the silica crystal structure obtained from simulation using the BKS potential with empirical studies with similar results. In addition, in ref. [27] calculated microstructure and density with this interaction potential giving results close to the results obtained from the experiment. The BKS models also have been applied in studies of amorphization of quartz under compression [28], the structural phase transformation from $\alpha$ to $\beta$ quartz [29, 30], the liquid-liquid phase transition in silica [31]. Although it produces well structural properties for silica and has been used widely, it exposes the quantitative deficiencies. Namely, in the work [32], the authors have shown that: the S-L-C triple point occurs at $13.4 \mathrm{GPa}$ in real silica, but at only 5.8 GPa in the model. Generally, the pressure range of the crystal stability areas is significantly lower in the model. In spite of its quantitative deficiencies, the BKS model describes the silica systems at the molecular level quite well.

The long-range Coulomb interactions are calculated with the standard Ewald summation technique. We used the Verlet algorithm to integrate the motion equation. MD time step is equal to $0.41 \mathrm{fs}$. The initial configuration is generated by placing all atoms randomly in a simulation box and heating it up to $5000 \mathrm{~K}$ to remove initial configuration. After that the model is cooled down from 5000 to $450 \mathrm{~K}$. Then, a long relaxation has been done to get equilibrium state using NPT ensemble (in NPT ensemble, number of atoms $(\mathrm{N})$, pressure $(\mathrm{P})$ and temperature $(\mathrm{T})$ are conserved). The structural data of considered models is determined by averaging over 1000 configurations during the last $5 \times 105$ time steps.

\section{Results and Discussion}

Firstly, as we have known, the radial distribution function (RDF) allows determining the average number of atoms at any given atomic distance. The average coordination number, bond length and bond angle will also determine via the RDF. Figure 1 displays RDF of contracted models. For Si-O pair, we show that at zero pressure, the first peak of RDF is very sharp. This demonstrates that at low 
pressure, local structure in amorphous silica or short range order structure is more order. Position of this peak located in $1.60 \AA$ which is in good agreement with the data reported in the experiment and simulation works $[19-20,33]$. At 5, 10, 15 and $20 \mathrm{GPa}$ pressure, the height of the first peaks of RDF strongly decreases and position shifts to the right. This indicates that the short range order structure is slightly dependent on pressure and the $\mathrm{Si}-\mathrm{O}$ bond length increases slightly with pressure. At 20,30 $\mathrm{GPa}$, the height of the first peak of RDF increases with pressure and the position shifts to the left. This indicates that beyond $20 \mathrm{GPa}$, the degree of short range order increases and the Si-O bond length decreases as pressure increases. We also show that beyond $20 \mathrm{GPa}$, the RDFs of Si-O pair have many peaks which indicate the formation of crystal structure. It can be explained that amorphous silica tends transforming to crystal structure under compression. For O-O pair, as can be seen that in the 0-30 GPa pressure range, the height of the first peak of RDFs of the O-O pair increases and its position shifts to left as pressure increases. It means that the $\mathrm{O}-\mathrm{O}$ bond length decreases with the increase of pressure. Similar to Si-O RDF, O-O RDF has many peaks at pressure of 20, $30 \mathrm{GPa}$. For Si-Si pair, it can be seen that as pressure increases, the location of the first peak of Si-Si pair of RDF shifts to the left and the first peak is splitted into two small peaks at 20, $30 \mathrm{GPa}$. At low pressure $(0,5 \mathrm{GPa})$, the $\mathrm{Si}$-Si bond length is 3.10 At high pressure $(10,15,20,30 \mathrm{GPa})$, there are two Si-Si bond lengths, one at about 3.06 and another at about 2.64 Á. Like to Si-O RDF and O-O RDF, Si-Si RDF also has many peaks at pressure 20, $30 \mathrm{GPa}$. This demonstrates one time again that the structure of $\mathrm{SiO}_{2}$ tends to form crystalline phases at high pressure $(20,30 \mathrm{GPa})$. From the above analysis, we can conclude that as under compression, the $\mathrm{Si}-\mathrm{O}$ bond length increases while the $\mathrm{Si}-\mathrm{Si}$ and $\mathrm{O}-\mathrm{O}$ bond lengths decreases. This means that $\mathrm{SiO}_{2}$ solid transform from amorphous to crystalline phase.

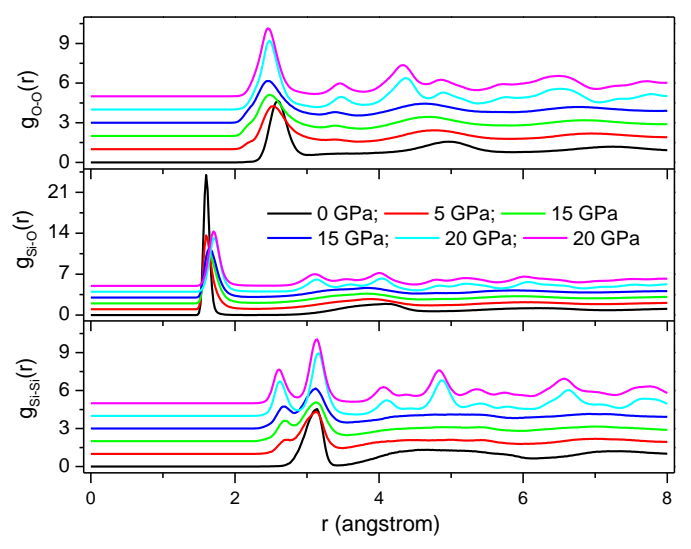

Figure 1. Radial distribution functions (RDF) g(r) of models for $\mathrm{Si}-\mathrm{Si}, \mathrm{Si}-\mathrm{O}$ and O-O pairs at $450 \mathrm{~K}$ and different pressure.

Next, we will clarify the origin of the change of $\mathrm{Si}-\mathrm{O}, \mathrm{O}-\mathrm{O}$ and $\mathrm{Si}-\mathrm{Si}$ bond lengths under compression. Figure 2, we can see that as pressure increases, there is a transformation in local environment of $\mathrm{Si}$ ions from tetrahedral- to octahedral- coordination. This can be consequences the decrease of $\mathrm{O}-\mathrm{Si}-\mathrm{O}$ bond angle. As can see Figure 3, the $\mathrm{O}-\mathrm{Si}-\mathrm{O}$ bond angle in $\mathrm{SiO}_{5}$ units is smaller than the one in $\mathrm{SiO}_{4}$ and larger than the one in $\mathrm{SiO}_{6}$ units. Therefore, the bond length between $\mathrm{O}$ and $\mathrm{O}$ ions in $\mathrm{SiO}_{5}$ units is smaller than the one in $\mathrm{SiO}_{4}$ and larger than the one in $\mathrm{SiO}_{6}$. It means that the increase of Si-O coordination number lead to the decrease of $\mathrm{O}-\mathrm{O}$ bond length. This result in increasing the Coulomb repulsion between $\mathrm{O}^{--}$and $\mathrm{O}^{--}$ions and the increase of Coulomb repulsion 
leads to elongation of the Si-O bond length. In the 0-20 GPa pressure range, the increase of coordination of $\mathrm{Si}$ with pressure will lead to the increase of $\mathrm{Si}-\mathrm{O}$ bond length. At $20 \mathrm{GPa}$, most of $\mathrm{Si}$ has octahedral coordination (as can see Figure 2a). In the 20-30 GPa pressure range, the increase of pressure will not lead to the increase of the Si-O bond length but lead to the decrease of the Si-O bond length (see Figure 1). For the Si-Si pair, the increase of pressure will result in the decrease of Si-Si bond length and the splitting of the first peak of Si-Si pair RDF. It can be explained as following, the increase of pressure will lead to increasing coordination number of $\mathrm{O}$ atoms. At low pressure $(0,5,10 \mathrm{GPa})$ most of $\mathrm{O}$ is surrounded by two $\mathrm{Si}$ atoms while at high pressure (>10 GPa), most of $\mathrm{O}$ is surrounded by three $\mathrm{Si}$ atoms (as can see Figure $2 \mathrm{~b}$ ). The increase of the coordination number consequences in the decrease of Si-O-Si bond angle as can be seen in Figure 4. At low pressure, most of the Si-O-Si is around 140-145 ${ }^{\circ}$. At high pressure, the $\mathrm{Si}-\mathrm{O}-\mathrm{Si}$ bond angle distribution has two peaks. For $\mathrm{OSi}_{2}$ linkage, the peaks locate at $105^{\circ}$ and $143^{\circ}$. For $\mathrm{OSi}_{3}$ linkage, the peaks locate at $95^{\circ}$ and $130^{\circ}$. The decrease of Si-O-Si angle leads to the decrease of $\mathrm{Si}-\mathrm{Si}$ bond length. This result in increasing the Coulomb repulsion and it one again leads to elongation of the $\mathrm{Si}-\mathrm{O}$ bond length. The distribution of $\mathrm{Si}-\mathrm{O}-\mathrm{Si}$ has two peaks this result in forming two $\mathrm{Si}$ $\mathrm{Si}$ bond distances. The Si-Si bond distance of 3.06 and 2.64 Á corresponds to two peaks of Si-O-Si bond angle distribution. Comparing to $\mathrm{Si}-\mathrm{O}-\mathrm{Si}$ and $\mathrm{O}-\mathrm{Si}-\mathrm{O}$ angles for amorphous $\mathrm{SiO}_{2}$ as can be seen in Figure 5, we show that bond angle distributions in $\mathrm{SiO}_{4}, \mathrm{SiO}_{5}$ and $\mathrm{SiO}_{6}$ units are quite close to $\mathrm{Si}-\mathrm{O}-\mathrm{Si}$ and $\mathrm{O}-\mathrm{Si}-\mathrm{O}$ angles at low and high pressure. This also means that at high pressure, the structure of $\mathrm{SiO}_{2}$ solid has stishovite crystal.

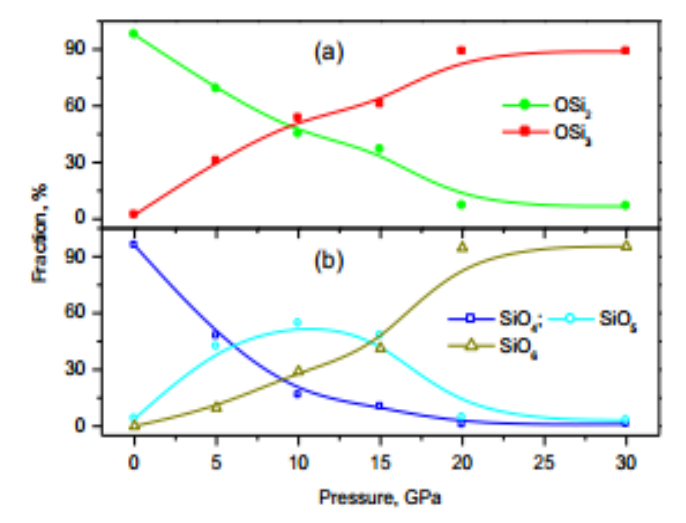

Figure 2. The coordination number distribution as a function of pressure: a) $\mathrm{Si}$ surrounds $\mathrm{O}$; b) $\mathrm{O}$ surrounds $\mathrm{Si}$.

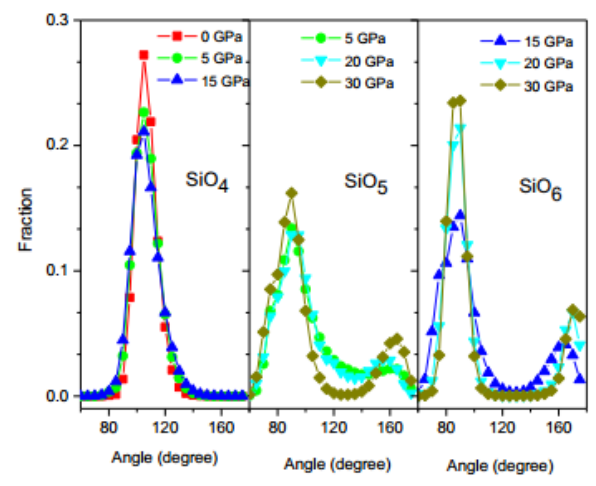

Figure 3. The O-Si-O bond angle distribution in $\mathrm{SiO}_{4}, \mathrm{SiO}_{5}$ and $\mathrm{SiO}_{6}$ units at different pressure. 


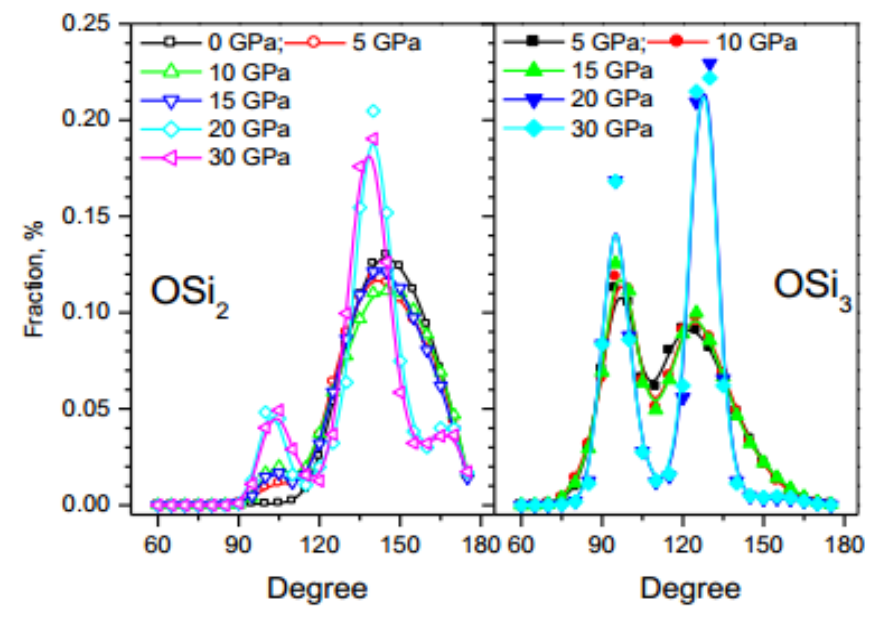

Figure 4. The Si-O-Si bond angle distribution under pressure.

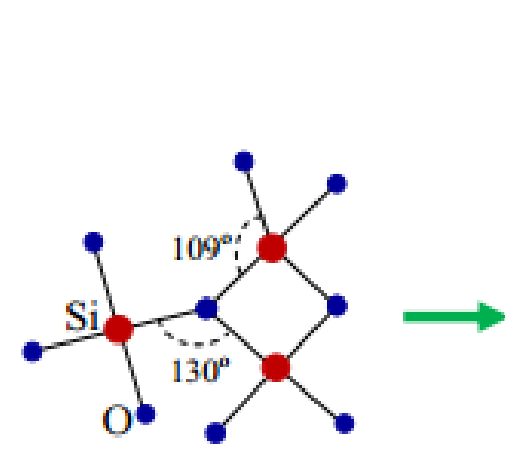

(a)

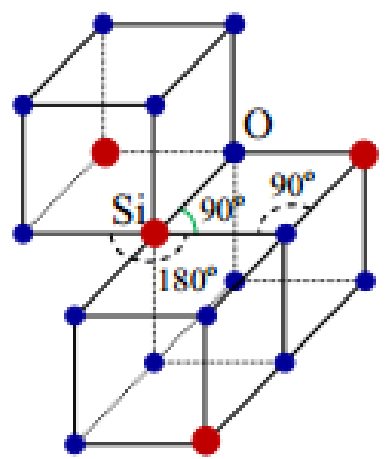

(b)

Figure 5. Schematics of basic structure units of amorphous $\mathrm{SiO}_{2}$ at low (a) and high (b) pressure. A clear structural change that shows the phase transformation from tetrahedral to octahedral structure (stishovite crystal) as pressure increases. It can be seen that $\mathrm{Si}-\mathrm{O}-\mathrm{Si}$ and $\mathrm{O}-\mathrm{Si}-\mathrm{O}$ angles are equal to $130^{\circ}, 109^{\circ}$ for low model and $90^{\circ}, 90^{\circ}$ for high model, respectively.

Finally, we use visualization to study atom arrangement distribution in amorphous $\mathrm{SiO}_{2}$. Figure 6 displays the snapshot of the atom arrangement distribution in the amorphous $\mathrm{SiO}_{2}$ at $0 \mathrm{GPa}$ and 30 GPa. It can be seen that at high pressure, atom arrangement is more order than ones at low pressure. This again demonstrates that the crystallization has occurred at high pressure. We will also display the modification number of structural units $\mathrm{SiO}_{6}$ in amorphous $\mathrm{SiO}_{2}$ system using $3 \mathrm{D}$ visualization. As we can see on Figure 7, the order degree of $\mathrm{SiO}_{6}$ units depends on pressure. At $30 \mathrm{GPa}$, most of structural units are $\mathrm{SiO}_{6}$ and they tend to form crystalline phase. Number of structural units $\mathrm{SiO}_{6}$ at 0 GPs is much less than ones at $30 \mathrm{GPa}$. Figure 7 also demonstrates that the structural units $\mathrm{SiO}_{6}$ form crystalline regions with different crystalline directions in model. In order to show more clearly, we visualize the spatial distribution of $\mathrm{SiO}_{4}, \mathrm{SiO}_{5}$ and $\mathrm{SiO}_{6}$ in the amorphous $\mathrm{SiO}_{2}$ at pressure of $0,10,20$ and $30 \mathrm{GPa}$. It can be seen in Figure 8, the distribution of coordination $\mathrm{SiO}_{x}$ units is not uniform but it tends to forms separated clusters (subnets) of $\mathrm{SiO}_{4}, \mathrm{SiO}_{5}$ and $\mathrm{SiO}_{6}$. 

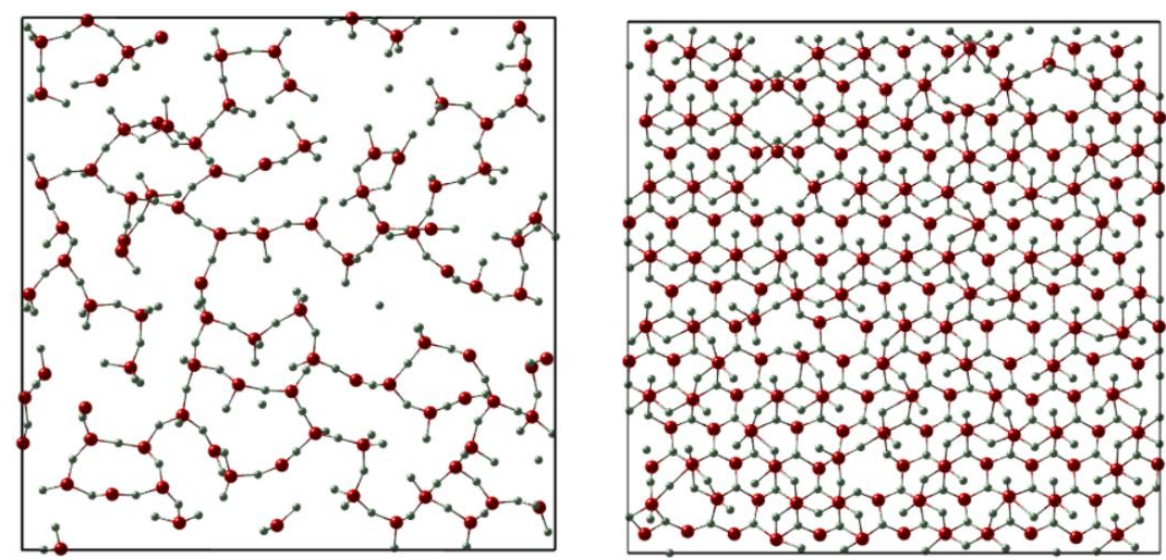

Figure 6. Snapshot of the atom arrangement distribution in the amorphous $\mathrm{SiO}_{2}$ at $0 \mathrm{GPa}$ (left) $30 \mathrm{GPa}$ (right): the red (large) sphere presents $\mathrm{Si}$ atom, the blue (small) sphere presents $\mathrm{O}$ atom.
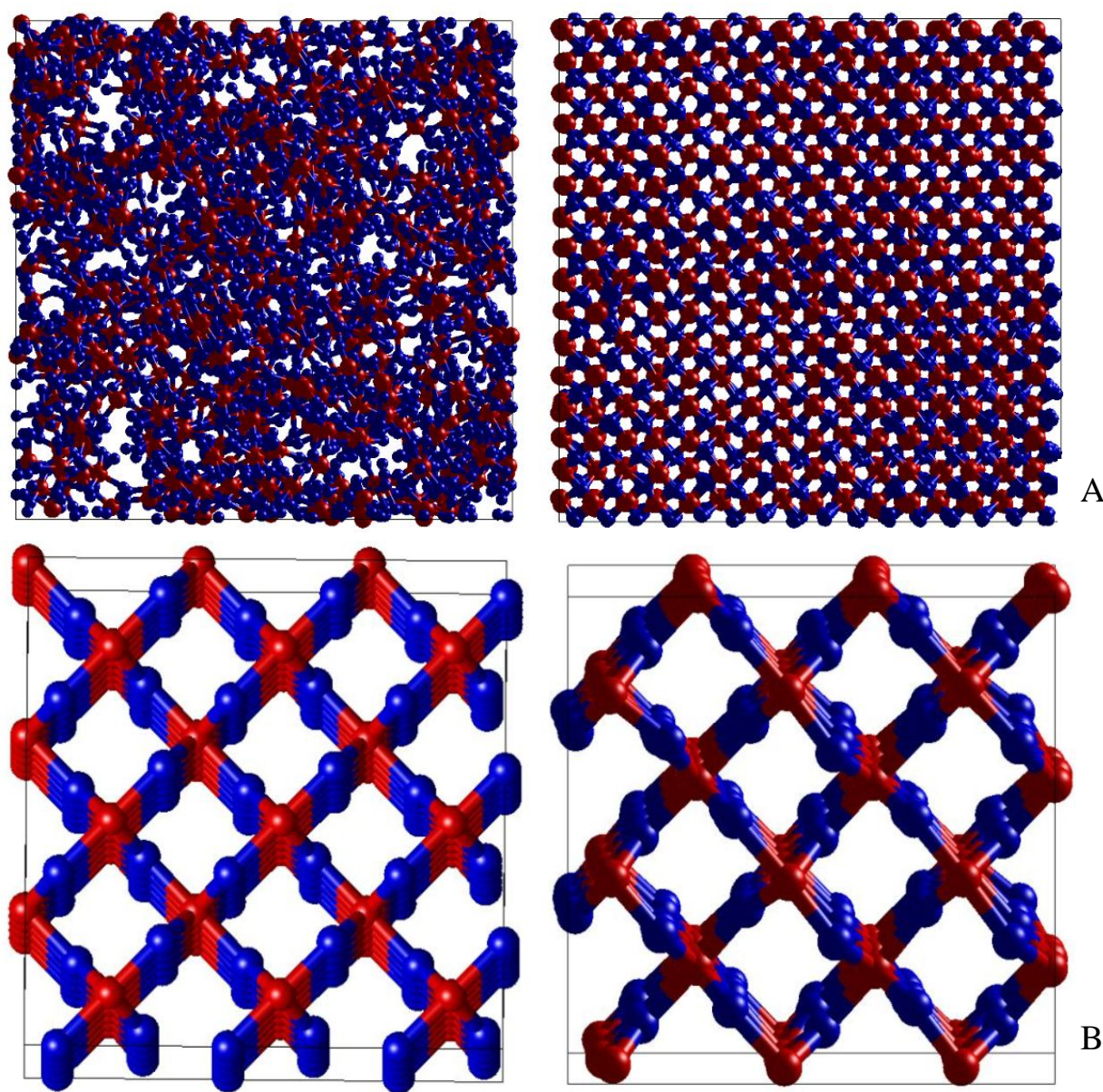

Figure 7. (A) Snapshot of the spattial distribution of $\mathrm{SiO}_{6}$ in the amorphous $\mathrm{SiO}_{2}$ at $0 \mathrm{GPa}$ (left) $30 \mathrm{GPa}$ (right): the red sphere presents $\mathrm{Si}$ atom, the blue sphere presents $\mathrm{O}$ atom. (B) The structure of stishovite crystalline (left) and the model of amorphous $\mathrm{SiO}_{2}$ that is compressed at $30 \mathrm{GPa}$ (right) 
It means that the structure of amorphous $\mathrm{SiO}_{2}$ comprises the mixture of $\mathrm{SiO}_{4}, \mathrm{SiO}_{5}$ and $\mathrm{SiO}_{6}$ clusters. Namely, the structure of $\mathrm{SiO}_{2}$ is the mixture of regions with different short range order. From the structural difference amongst regions, we can see that the structure of $\mathrm{SiO}_{2}$ consists of structural phases is that $\mathrm{SiO}_{4}-, \mathrm{SiO}_{5}$ - and $\mathrm{SiO}_{6}$-phases, where $\mathrm{SiO}_{x}(x=4,5,6)$ phases are the phase formed by $\mathrm{SiO}_{x}$ units, respectively. It can be seen that at low pressure $(0 \mathrm{GPa})$, the regions with $\mathrm{SiO}_{4}$-phase are linked each to other forming a large region with the expanse almost whole model. The regions with $\mathrm{SiO}_{5}$ - and $\mathrm{SiO}_{6}$-phases are small and localized at different locations forming separated regions. As pressure increases, the regions with $\mathrm{SiO}_{5}$-and $\mathrm{SiO}_{6}$-phases are expanded and the regions with $\mathrm{SiO}_{4}$-phase are shrunk. At pressure of $30 \mathrm{GPa}$, the regions with $\mathrm{SiO}_{4}$ - and $\mathrm{SiO}_{5}$-phases are shrunk, whereas the regions with $\mathrm{SiO}_{6}$-phase are expanded almost the whole model. Especially, at pressure of $30 \mathrm{GPa}$, the structure of $\mathrm{SiO}_{2}$ is $\mathrm{SiO}_{6}$-phase with the high order degree (long order structure) and they tend to transformation into crystal structure, namely it is stishovite crystal as above analyzed.
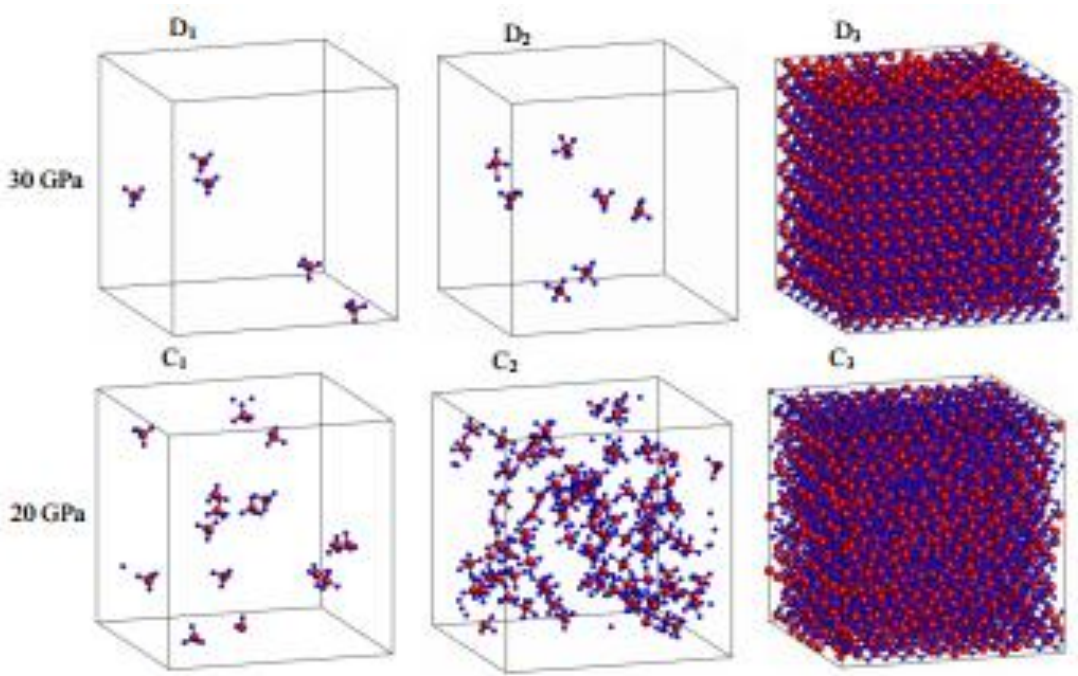

$\mathrm{C}_{2}$
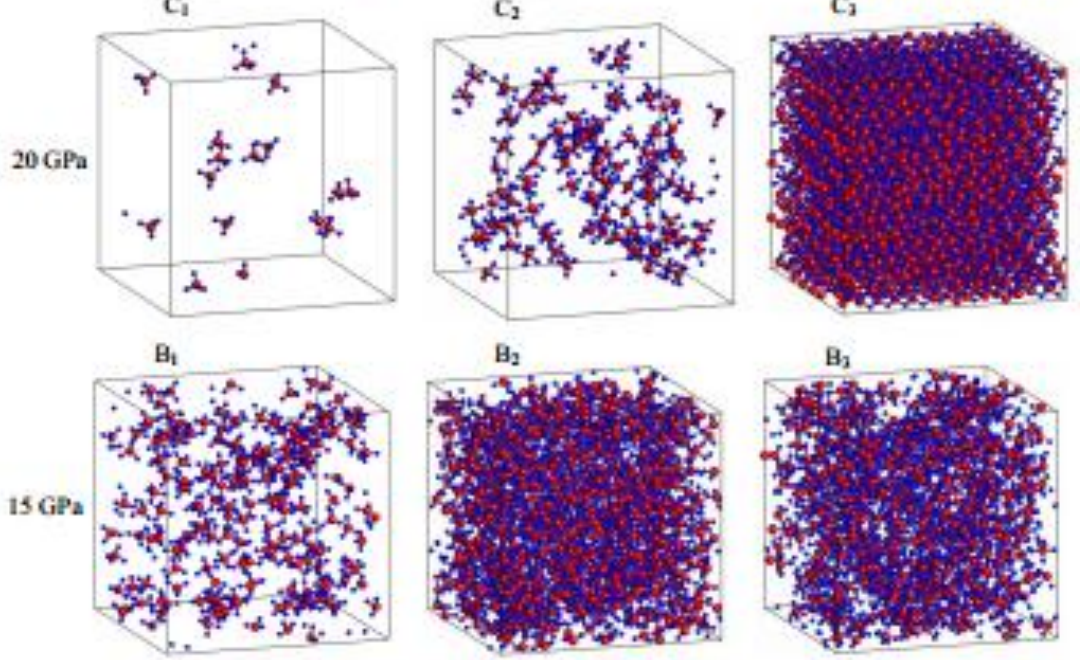

$\mathrm{B}_{2}$
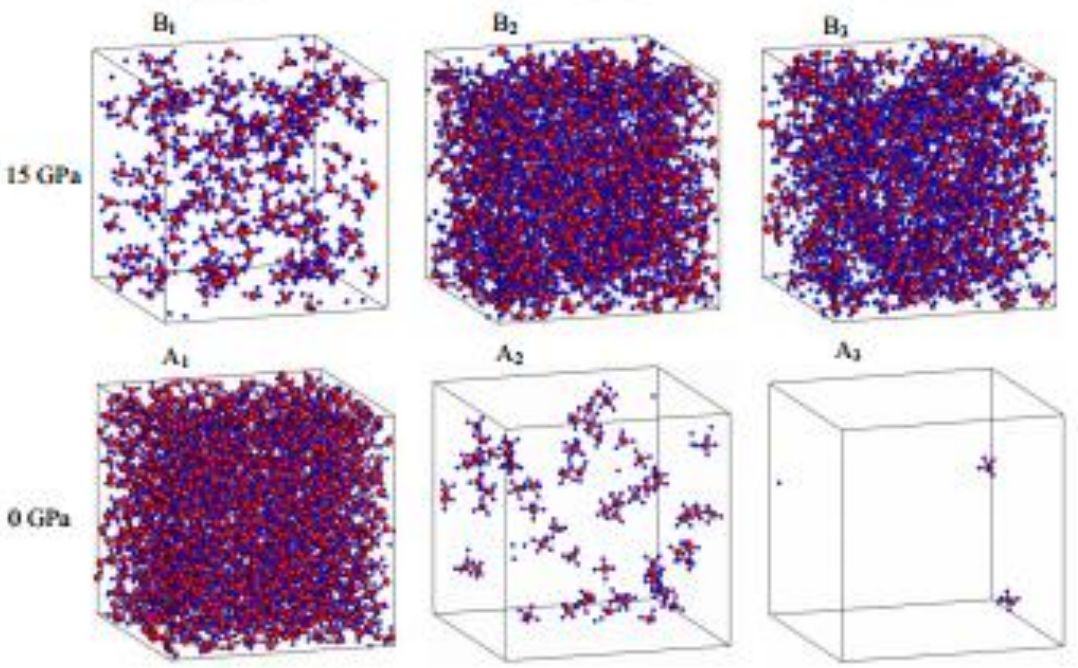

Figure 8. Spatial distribution of $\mathrm{SiO}_{4}, \mathrm{SiO}_{5}$ and $\mathrm{SiO}_{6}$ in the amorphous $\mathrm{SiO}_{2}$ at pressure of $0,15,20$ and $40 \mathrm{GPa}$ :

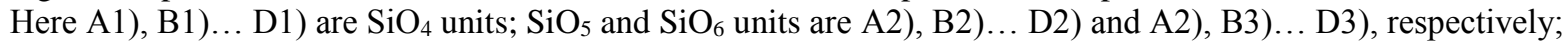
$\mathrm{Si}$ and $\mathrm{O}$ atoms are in red and blue ball, respectively. 


\section{Conclusion}

The structure transition and crystallization of amorphous silica under compression have been investigated. Several results are demonstrated as follows

(i) There is a structural transformation from tetrahedral- to octahedral- network through $\mathrm{SiO}_{5}$ units. In the 5-15 GPa pressure range, structural transformation occurs strongly and there are three structural phases corresponding to $\mathrm{SiO}_{4-}^{-}, \mathrm{SiO}_{5-}$, and $\mathrm{SiO}_{6}$ ones.

(ii) At $15 \mathrm{GPa}$, octahedral-network is dominant. When pressure is higher than $20 \mathrm{GPa}$, octahedral-network tends to transform to stishovite crystalline phase. Namely, the structural units $\mathrm{SiO}_{6}$ form stishovite crystalline regions with different crystalline directions in model. However, the crystalline mechanism in amorphous $\mathrm{SiO}_{2}$ will be focused on the next researchs.

\section{Acknowledgements}

This research is funded by Vietnam National Foundation for Science and Technology Development (NAFOSTED) under grant number 103.02-2018.312. This work was supported by the Domestic Master/PhD Scholarship Programme of Vingroup Innovation Foundation under grant number VINIF.2019.TS.70

\section{References}

[1] A.R. Oganov, M.J. Gillan, G.D. Price, Structural stability of silica at high pressures and temperatures, Physical Review B 71 (2010) 064104.

[2] V.P. Prakapenka, Guoyin Shen, L.S. Dubrovinsky, M.L. Rivers, S.R. Sutton, High pressure induced phase transformation of $\mathrm{SiO}_{2}$ and $\mathrm{GeO}_{2}$ : difference and similarity, Journal of Physics and Chemistry of Solids 65 (2004) 1537-1545.

[3] K.J. Kingma, R.E. Cohen, R.J. Hemley, H.K. Mao, Transformation of stishovite to a denser phase at lowermantle pressures, Nature 374 (1995) 243-245.

[4] S.R. Shieh, T.S. Duffy, B. Li, Strength and Elasticity of $\mathrm{SiO}_{2}$ across the Stishovite-CaCl $\mathrm{C}_{2}$-type Structural Phase Boundary, Physical Review Letters 89 (2002) 255507.

[5] S. Ono, K. Hirose, M. Murakami, M. Isshiki, Post-stishovite phase boundary in $\mathrm{SiO}_{2}$ determined by in situ X-ray observations, Earth and Planetary Science Letters 197 (2002) 187-192.

[6] D.M. Teter, R.J. Hemley, G. Kresse, J. Hafner, High pressure polymorphism in silica, Physical Review Letters 80 (1998) 2145-2148.

[7] L.S. Dubrovinsky, N.A. Dubrovinskaya, S.K. Saxena, F. Tutti, S. Rekhi, T.L. Bihan, G. Shen, J. Hu, Pressureinduced transformations of cristobalite, Chemical Physics Letters 333 (2001) 264-270.

[8] D. Andrault, G. Fiquet, F. Guyot, M. Hanfland, Pressure-induced Landau-type transition in stishovite, Science 282 (1998) 720-724.

[9] D. Andrault, R.J. Angel, J.L. Mosenfelder, T.L. Bihan, Equation of state of stishovite to lower mantle pressures, American Mineralogist 88 (2003) 301-307.

[10] L.T. San, N.V. Hong, P.K. Hung, Polyamorphism of liquid silica under compression based on five orderparameters and two-state model: a completed and unified description, High Pressure Research 36 (2016) 187197.

[11] F. Mauri et al., Si-O-Si bond-angle distribution in vitreous silica from first-principles ${ }^{29} \mathrm{Si}$ NMR analysis, Physical Review B 62 (2000) R4786.

[12] Wei Liu et al., Multiple pathways in pressure-induced phase transition of coesite, Proceedings of the National Academy of Sciences 114 (2017) 12894-12899. 
[13] E. Bykova et al., Metastable silica high pressure polymorphs as structural proxies of deep Earth silicate melts, Nature communications 9 (2018) 4789.

[14] S. Petitgirard et al., Magma properties at deep Earth's conditions from electronic structure of silica, Geochem. Perspect. Lett 9 (2019) 32-37

[15] Min Wu, Yunfeng Liang, Jian-Zhong Jiang and John S. Tse, Structure and properties of dense silica glass, Scientific reports 2 (2012) 398.

[16] Q.Y. Hu, J.F. Shu, A. Cadien, Y. Meng, W.G. Yang, H.W. Sheng, H.K. Mao, Polymorphic phase transition mechanism of compressed coesite, Nature Communications 6 (2015) 6630.

[17] James Badro et al., Theoretical study of a five-coordinated silica polymorph, Phys. Rev. B 56 (1997) R5797.

[18] B.W.H. van Beest, G.J. Kramer, R.A. van Santeen, Force fields for silicas and aluminophosphates based on ab initio calculations, Physical Review Letters 64 (1990) 1955.

[19] P.K. Hung, N.V. Hong, L.T. Vinh, Diffusion and structure in silica liquid: a molecular dynamics simulation, Journal of Physics: Condensed Matter 19 (2007) 466103.

[20] Neng Li et al., Densification of a continuous random network model of amorphous $\mathrm{SiO}_{2}$ glass, Physical Chemistry Chemical Physics 16 (2014) 1500-1514.

[21] K. Vollmayr, W. Kob, and K. Binder, Cooling-rate effects in amorphous silica: A computer-simulation study, Physical Review B 54 (1996) 15808.

[22] R.L.C. Vink and G.T. Barkema, Large well-relaxed models of vitreous silica, coordination numbers, and entropy, Physical Review B 67 (2002) 245201.

[23] T.F. Soules, G.H. Gilmer, M. J. Matthews, J.S. Stolken, M.D. Feit, Silica molecular dynamic force fields-A practical assessment. Journal of non-crystalline solids 357 (2011) 1564-1573.

[24] R.G.D. Valle and H.C. Andersen, Molecular dynamics simulation of silica liquid and glass, The Journal of chemical physics 97 (1992) 2682-2689.

[25] D. Herzbach, K. Binder, M.H. Müser, Comparison of model potentials for molecular-dynamics simulations of silica, The Journal of chemical physics 123 (2005) 124711.

[26] J. Horbach, W. Kob, Static and dynamic properties of a viscous silica melt, Physical Review B 60 (1999) 31693181.

[27] P.K. Hung, N.T.T. Ha, M.T.Lan, N.V. Hong, Spatial heterogeneous distribution of $\mathrm{SiO}_{\mathrm{x}} \rightarrow \mathrm{SiO}_{\mathrm{x} \pm 1}$ reactions in silica liquid, The Journal of chemical physics 138 (2013) 244505.

[28] J.S. Tse, D.D. Klug, Mechanical instability of $\alpha$-quartz: A molecular dynamics study, Physical review letters 67 (1991) 3559.

[29] H. Kimizuka, H. Kaburaki, Y. Kogure, Molecular-dynamics study of the high-temperature elasticity of quartz above the $\alpha-\beta$ phase transition, Physical Review B 67 (2003) 024105.

[30] M. Muser, K. Binder, Molecular dynamics study of the $\alpha-\beta$ transition in quartz: elastic properties, finite size effects, and hysteresis in the local structure, Physics and Chemistry of Minerals 28 (2001) 746-755.

[31] I. Saika-Voivod, F. Sciortino, P.H. Poole, Computer simulations of liquid silica: Equation of state and liquidliquid phase transition, Physical Review E 63 (2000) 011202.

[32] Ivan Saika-Voivod, Francesco Sciortino, Tor Grande, Peter H. Poole, Phase diagram of silica from computer simulation. Physical Review E 70 (2004) 061507.

[33] N. Li, R. Sakidja, S. Aryal, W. Ching, Densification of a continuous random network model of amorphous $\mathrm{SiO}_{2}$ glass, Physical Chemistry Chemical Physics 16 (2014) 1500-1514. 